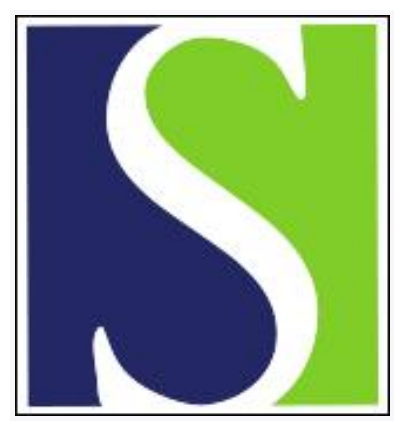

Scand J Work Environ Health 2005;31(2):122-131

https://doi.org/10.5271/sjweh.859

Issue date: Apr 2005

Risk factors for persistent elbow, forearm and hand pain among computer workers

by Lassen CF, Mikkelsen S, Kryger Al, Andersen JH

Affiliation: Kræftens Bekæmpelse, Institut for Epidemiologisk Kræftforskning, Strandboulevarden 49, DK-2100 Ø, København, Denmark. funch@cancer.dk

The following article refers to this text: 2008;34(2):113-119

Key terms: computer work; computer worker; elbow pain; forearm pain; hand pain; musculoskeletal pain; NUDATA study; prognosis; recovery; risk factor

This article in PubMed: www.ncbi.nlm.nih.gov/pubmed/15864906

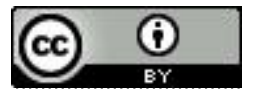




\title{
Risk factors for persistent elbow, forearm and hand pain among computer workers
}

\author{
by Christina F Lassen, MD, ${ }^{1}$ Sigurd Mikkelsen, MDs, ${ }^{1}$ Ann I Kryger, PhD, ${ }^{1}$ Johan H Andersen, PhD ${ }^{2}$
}

\begin{abstract}
Lassen CF, Mikkelsen S, Kryger Al, Andersen JH. Risk factors for persistent elbow, forearm and hand pain among computer workers. Scand J Work Environ Health 2005;31(2):122-131.
\end{abstract}

\begin{abstract}
Objectives This study examined the influence of work-related and personal factors on the prognosis of "severe" elbow, forearm, and wrist-hand pain among computer users.

Methods In a 1-year follow-up study of 6943 computer users, 673 (10\%) participants reported "quite a lot" or more trouble due to elbow, forearm, or wrist-hand pain during the 12 months preceding the baseline questionnaire. Pain status (recovery versus persistence) at follow-up was examined in relation to computer work aspects and ergonomic, psychosocial, and personal factors by questionnaire. In addition, data on objectively recorded computer usage were available for $42 \%$ of the participants during the follow-up, measured by means of a program (WorkPaceRecorder) installed on their computers.

Results During the follow-up, two-thirds of the baseline cases improved to some degree, but only one-third experienced substantial improvement. The prognosis was not influenced by mouse or keyboard work (time, speed, micropauses, and average activity periods) or ergonomic workplace conditions. Keyboard times, however, were very low. Pain in other regions was a predictor of persistent arm pain. Except for time pressure, female gender, and type-A behavior, the prognosis seemed independent of psychosocial workplace factors and personal factors. A few cases with severe pain were affected at a level which could be compared to clinical pain conditions.

Conclusions Our results do not support the hypothesis that computer work activity or ergonomic conditions influence the prognosis of severe arm pain. This result is somewhat surprising and should be tested in other studies. Pain in other regions implies a poorer prognosis for arm pain.
\end{abstract}

Key terms computer work; musculoskeletal pain; NUDATA study; prognosis; recovery; risk factor.

In 2003, 62\% of all Danish employees used a personal computer at work, and $83 \%$ of the population had access to a personal computer at home (1). Results from a surveillance study of the Danish labor force in 19902000 showed that the prevalence of self-reported computer use for $75 \%$ of the workday increased from $4.4 \%$ of workers in 1990 to $11 \%$ in 1995 and further to $21 \%$ in 2000 (2).

Several prospective studies have found associations between computer work and incident upper-limb pain (3-7). The duration of computer work (daily or weekly hours) seems to increase the risk for upper-limb pain approximately two to three times for those with many hours of computer use when they are compared with those with few hours of computer use (3-5). There is no evidence of a threshold effect in the association between exposure and outcome $(4,5,7)$. Associations between usage time and symptoms may reflect a causal relation or a computer-related exacerbation of recurrent musculoskeletal problems, which are common in the general population (8).

Factors associated with persistent pain may differ from etiologic factors. In the clinical setting, knowledge of factors that predict symptom reduction or persistence is important in the counseling of patients with pain related to computer work. Should the patient be advised to change the ergonomic arrangement of the workstation or to reduce or completely avoid computer work? Such advice may influence patients' work situation and job security and should be based on scientifically sound 
evidence. We are not aware of other studies on the prognosis of pain related to computer work.

Studies of the prognosis of other work-related pain in the upper extremities or in other regions have shown that the prognosis can be influenced by baseline pain severity, pain coping style, and work-related physical and psychosocial risk factors $(9,10)$. The aim of the present study was to evaluate aspects of computer work, work-related psychosocial factors, and personal factors as risk factors in the prognosis of "severe" arm pain.

\section{Study population and methods}

\section{Study population}

The study on neck and upper-extremity disorders among technical assistants (the NUDATA study) is a 1-year follow-up study of a cohort of 9480 computer workers, defined by educational title and membership of the Danish Association of Professional Technicians by January 2000. The 7252 qualified engineering technical assistants and 2228 machine technicians were employed in 3527 public and private companies doing computer-aided design, graphics and lay out, word processing, data entry tasks, and noncomputer worktasks. The cohort has been described in detail in previous papers $(4,5)$.

The participants completed a self-administered baseline questionnaire, and the respondents at baseline completed a questionnaire at follow-up. The participation rate at baseline was $73 \%(\mathrm{~N}=6943)$, and at follow-up it was $82 \%(\mathrm{~N}=5658)$.

The follow-up respondents and nonrespondents did not differ with respect to the baseline mouse or keyboard time, gender, or severe elbow or forearm pain. However, relatively more nonrespondents had severe hand pain, and relatively more were in the younger age groups.

At baseline, 821 participants $(12 \%)$ reported that they had been troubled quite a lot, much or very much by pain or discomfort in the right elbow, forearm, or wrist-hand during the past 12 months. Among these baseline pain cases, $673(82 \%)$ completed the followup questionnaire (289 right elbow cases, 295 right forearm cases, and 432 right wrist-hand cases). In the following, they are referred to as "severe" arm pain cases.

\section{Questionnaire}

Information about musculoskeletal symptoms in the neck, right and left shoulders, elbows, forearms, wristhands, and the lower back were obtained by questionnaire. For each of these regions respondents reported the degree to which they had been troubled by pain or discomfort during the past 12 months (not at all, very little, little, somewhat, quite a lot, much, very much). The response alternatives were attributed scores from 0 to 6 . They reported pain or discomfort during the past 12 months (yes, no) and pain during the past 7 days (no, very mild, mild, mild to moderate, moderate, moderateto-severe, severe, and very severe pain). Pain in the hips, knees, and feet (yes, no) was also reported for the past 12 months. Identical questions were posed in the baseline questionnaire and that of the follow-up.

At the follow-up, the respondents reported their total number of sickness absence days due to regional pain or discomfort during the past 12 months.

Data were obtained concerning active mouse time (right-hand, left-hand, both-hand use) and keyboard time in hours per week. Identical questions were posed at the baseline and follow-up. Self-reported information about ergonomic factors was obtained with the baseline questionnaire, but not at the follow-up. General satisfaction with the physical workplace arrangement was reported. At the follow-up the respondents reported whether or not they had changed their computer work because of neck or arm pain ("reduced computer work time", "changed hand or alternated between hands, when using the mouse", "changed input device", "changed workstation arrangement", "other changes").

If respondents were not employed at the time of the follow-up, they reported whether their employment situation was related to pain in a specific region (no; yes, partly; yes, exclusively). Information about job demands, job control, and social support from colleagues and supervisors was obtained by use of the Copenhagen Psychosocial Questionnaire (11), which is based on the Job Content Questionnaire (12). We also included two questions designed to measure "time pressure".

Information was obtained about height, weight, personal characteristics (negative affectivity, type-A behavior), leisure-time physical activity, and current medical condition potentially related to musculoskeletal pain. Detailed information about the questionnaire data is given in reports by Andersen et al (4), Kryger et al (5), and Lassen et al (13). The respondents with at least moderate 7-day pain were invited to a clinical examination, including the assessment of physical function by the DASH (Disabilities of the Arm, Shoulder, and Hand) outcome measure, ranging from 0 to 100 , where 100 represents maximum disability (14).

\section{Objective data on computer use}

At baseline, all the members of the cohort were asked to install a software program, WorkPaceRecorder ${ }^{\circledR}$ (Niche Software, New Zealand) (WPR), on their personal computer at work. The program was supplied on a floppy disc enclosed in the questionnaire. The program recorded all mouse and keyboard activities and stored the daily results in a log file, which was returned to the 
project group after up to 52 weeks of recording. The installation had the following requirements: permission to install the program, specified platforms, use of personal log-on identification, and the use of only one computer. The registration period could be less than 52 weeks (eg, if the participant left the company). In all, 2146 participants (38\% of the participants at the followup) returned recorded data. Among the 673 severe armpain cases in the study, $281(42 \%)$ returned these data. Those who returned objective data did not differ from those who did not with respect to age and gender or questionnaire keyboard time, but they reported slightly more questionnaire mouse time and had a poorer prognosis.

Periods of mouse and keyboard activity were recorded as follows: mouse events (clicks or movements) or keystrokes occurring without intervals of 5 seconds or more. The mouse and keyboard exposure durations were the weekly sum of these periods in hours per week ("mouse time" and "keyboard time"). The mouse and keyboard micropauses were nonusage periods of 5 to 10 seconds between the mouse and keyboard activity periods, respectively. The weekly total of these micropauses was recorded. The total number of mouse clicks and keystrokes per week and the average duration of mouse and keyboard activity periods were also extracted from the recorded data.

\section{Data analysis}

Outcomes. The outcomes were defined as pain reduction versus pain persistence. The reduction in severe right elbow, forearm, or wrist-hand pain was defined as a reduction in the regional pain score by at least three scale points from the baseline to the follow-up, and, if such a degree of pain reduction had not occurred, the pain state at follow-up was labeled "persistent" pain. This label covered minor pain reductions, unchanged pain, and, in some cases, pain aggravation (table 1).

Pain reduction in the three regions was correlated (Spearman correlation coefficients $0.42-0.50$; Cronbach's alpha coefficient $=0.71$ for the sum scale of the three items). To increase the analytical power, a common variable was established for arm pain reduction. "Severe" arm pain at baseline was defined as "severe" pain in any of the three regions. Arm pain reduction (yes, no) was defined as follows: (i) if severe pain was present in only one case region, significant pain reduction was defined as a pain score reduction of at least three scale points; (ii) if severe pain was present in two regions, significant pain reduction was defined as a summed pain score reduction for at least five scale points; and (iii) if severe pain was present for all of the three regions, significant reduction was defined as a summed pain reduction score of at least seven scale points. These rules implied that, if more than one region was involved, a significant reduction (3 scale points) in the pain score in at least one region and some reduction in the other region(s) were required. Since these rules were somewhat arbitrary, pain reductions based on a weaker and a stronger reduction criterion were also examined. The weaker criterion was a pain reduction of three scale points, independently of the number of regions involved. The stronger criterion was

Table 1. Distribution of severe elbow, forearm, and wrist-hand cases at baseline by degree of being troubled in the 12 months prior to the baseline questionnaire and during 12 months of follow-up. Figures in parentheses are scores.

\begin{tabular}{|c|c|c|c|c|c|c|c|c|}
\hline \multirow[t]{2}{*}{ Baseline pain } & \multicolumn{8}{|c|}{ Follow-up pain (score) ${ }^{a}$} \\
\hline & $\begin{array}{l}\text { None } \\
(0)\end{array}$ & $\begin{array}{c}\text { Very little } \\
(1)\end{array}$ & $\begin{array}{l}\text { Little } \\
(2)\end{array}$ & $\begin{array}{c}\text { Somewhat } \\
\text { (3) }\end{array}$ & $\begin{array}{l}\text { Quite a lot } \\
\text { (4) }\end{array}$ & $\begin{array}{l}\text { Much } \\
(5)\end{array}$ & $\begin{array}{l}\text { Very much } \\
(6)\end{array}$ & Total \\
\hline \multicolumn{9}{|l|}{ Elbow } \\
\hline Quite a lot (4) & 51 & 8 & $33^{b}$ & $42^{b}$ & $32^{b}$ & $8^{b}$ & $4^{b}$ & 178 \\
\hline Much (5) & 4 & 4 & 11 & $24^{b}$ & $17^{b}$ & $7^{b}$ & $2^{b}$ & 69 \\
\hline Very much (6) & 5 & 0 & 4 & 4 & $12^{b}$ & $11^{b}$ & $5^{b}$ & 41 \\
\hline Total & 60 & 12 & 48 & 70 & 61 & 26 & 11 & 288 \\
\hline \multicolumn{9}{|l|}{ Forearm } \\
\hline Quite a lot (4) & 41 & 21 & $31^{b}$ & $51^{b}$ & $28^{b}$ & $11^{b}$ & $2^{b}$ & 185 \\
\hline Much (5) & 5 & 4 & 17 & $17^{b}$ & $16^{b}$ & $16^{b}$ & $7^{b}$ & 82 \\
\hline Very much (6) & 2 & 0 & 1 & 6 & $5^{b}$ & $7^{b}$ & $5^{b}$ & 26 \\
\hline Total & 48 & 25 & 49 & 74 & 49 & 34 & 14 & 293 \\
\hline \multicolumn{9}{|l|}{ Wrist-hand } \\
\hline Quite a lot (4) & 45 & 18 & $48^{b}$ & $73^{b}$ & $60^{b}$ & $25^{b}$ & $11^{\mathrm{b}}$ & 280 \\
\hline Much (5) & 11 & 8 & 13 & $19^{b}$ & $23^{b}$ & $17^{b}$ & $8^{b}$ & 99 \\
\hline Very much (6) & 3 & 2 & 3 & 8 & $5^{b}$ & $16^{b}$ & $13^{b}$ & 50 \\
\hline Total & 59 & 28 & 64 & 100 & 88 & 58 & 32 & 429 \\
\hline
\end{tabular}

a Missing for 1 elbow case, 2 forearm cases, and 3 wrist-hand cases.

b Participants with less than three scale points of pain reduction from baseline to follow-up ("persistent" pain). 
a reduction of three, six, and nine summed scale points if one, two or three regions, respectively, were involved. If these criteria for arm pain reduction were not met, arm pain was considered persistent. The three criteria are referred to as " $3,3,3$ ", " $3,5,7$ ", and " $3,6,9$ ", the figures indicating the scale point reduction criterion if there were one, two, or three regions with severe pain at baseline.

Since $95 \%$ of the respondents used the mouse in the right hand, only the results for the right-sided outcomes are reported.

The associations between the pain outcomes and the potential determinants were analyzed with multiple logistic regression models. All the examined covariates were included in the models whether statistically significant or not. We report the effects of the covariates as risk factors for arm pain persistence. The determinants and their parameterization as covariates in the models are described later in this report.

Questionnaire covariates. The following baseline variables were considered potential determinants of persistent arm pain: mouse time (continuous and in 10-hour categories), keyboard time (continuous and in 5-hour categories), forearm-wrist support during mouse use (yes, no), forearm-wrist support during keyboard use (yes, no), "abnormal" keyboard position (keyboard center to the left or the right of the body), "abnormal" mouse position (mouse position $>40 \mathrm{~cm}$ to the right of the shoulder or $>40 \mathrm{~cm}$ from the front edge of the desk), chair or desk not adjusted to individual needs, and dissatisfaction with workplace arrangement. Job demands, job control, and social support from colleagues were considered dichotomous variables (high, low), and job strain was defined as the interaction between the demand and control variables. Responses concerning time pressure were collapsed into one scale, and the scale values were dichotomized into high and low time pressure.

Present pain in any outcome region, and pain in regions outside the case regions were also considered. Present pain in a specific outcome region was defined as moderate 7-day pain or more (yes, no). Present arm pain was defined as present pain in any of the three regions. Widespread pain was defined as the number of regions outside the three right-sided outcome regions (ie, neck, right shoulder, left shoulder, elbow, forearm, and wrist-hand, low back, hips, knees, or feet) in which the respondents reported any 12-month pain, categorized into none, $1-2$ regions, $3-4$ regions, and $\geq 5$ regions.

Finally, the effects of the following personal factors were considered: age (continuous), gender, body mass index (BMI) $\geq 30$ (yes, no), negative affectivity; type-A behavior, leisure-time physical activities (high, low), and medical conditions (yes, no).
Objective computer-use covariates. The number of mouse and keyboard micropauses, mouse clicks, and keystrokes were highly correlated with the corresponding mouse and keyboard times. Micropauses were therefore converted to the number of micropauses per hour, and clicks and keystrokes were recorded as clicks and keystrokes per minute (mouse and keying speed).

The means of weekly mouse and keyboard times, micropauses per hour, speed, and average activity periods during the first 4 weeks of recording were considered to represent objective aspects of computer use at baseline. These variables were introduced in logistic regression models instead of questionnaire mouse and keyboard times as continuous variables, or they were categorized into low, medium, and high levels. Since the data on objective computer use were based on fewer observations than the questionnaire data were, only questionnaire covariates with a statistically significant effect of $\mathrm{P} \leq 0.25$ were introduced into these models.

Interactions. Since the effects of ergonomic factors may depend on the duration of mouse and keyboard times, interaction terms between relevant covariates were introduced into the models (eg, between abnormal mouse position and mouse time). Similarly, the effects of micropauses, mouse and keying speed, and average activity periods may depend on mouse or keyboard times. Interaction terms for these objective computer usage aspects were also introduced into the models that examined the effects of the objective aspects of computer use.

Exposure changes from baseline to follow-up. Changes larger than \pm 5 hours/week of self-reported mouse and keyboard time from the baseline to the follow-up were introduced into the models.

For objective data on computer use (mouse and keyboard times, micropauses, speed, and average activity periods), the differences between the means of the first 4 weeks of recording and the last 4 weeks before the follow-up questionnaire was completed were introduced into the models as continuous variables, or they were categorized into less, unchanged, or more by appropriate cut points.

\section{Results}

Detailed distributions of the pain categories or scores for the elbow, forearm, and wrist-hand cases at baseline and at follow-up are shown in table 1. Persistent pain was found in $68 \%(197 / 288)$ of the elbow cases, in $67 \%(196 / 293)$ of the forearm cases, and in $74 \%$ (318/ 429) of the wrist-hand cases. 
At baseline, 410 respondents $(61 \%)$ had severe pain in one region, $183(27 \%)$ experienced pain in two regions, and $80(12 \%)$ had pain in three regions. At the follow-up, "severe" pain persisted in 284 (70\%), 117 $(64 \%)$, and $55(70 \%)$ of the respondents, respectively, according to the intermediate 3,5,7 criterion. According to the weaker 3,3,3 criterion, 433 respondents $(64 \%)$ had persistent pain, and, according to the stronger 3,6,9 criterion, $503(75 \%)$ respondents had persistent pain.

\section{Questionnaire data}

Table 2 shows the distribution of the covariates and their relations to persistent arm pain (3,5,7 criterion), including the results of the logistic regression analyses with all the covariates included in the model. Table 3 shows the results of the logistic regression analyses for the six outcomes examined. The models included continuous mouse and keyboard times irrespective of their statistical significance, and also other covariates if retained in the models with effects statistically significant at $\mathrm{P} \leq 0.25$.

Increasing mouse and keyboard times tended to increase the risk for persistent pain, but the effects were not statistically significant at $\mathrm{P} \leq 0.05$, except for the effect of mouse time on persistent arm pain (3,6,9-criterion). Forearm-wrist support during mouse use increased the risk for persistent wrist-hand pain, contrary to expectations, and an unadjusted desk increased the risk of persistent forearm pain. Dissatisfaction with the physical workplace arrangement seemed to protect against persistent arm pain (3,6,9 criterion). Forearm-wrist support during keyboard use and abnormal mouse or keyboard position were not statistically significant risk factors at a P-value level of $\leq 0.25$ in any of the models. Only $24(3.6 \%)$ had an unadjusted chair, and this variable was not included in the regression analyses.

Table 2. Distribution of the questionnaire covariates and their associations with persistent arm pain (3,5,7 criterion) —number ( $N)$ in the specified covariate category, percentage (\%) of number with persistent arm pain, crude odds ratios (OR) and adjusted odds ratios $(\mathrm{OR})$ with $95 \%$ confidence intervals $(95 \% \mathrm{Cl})$ from the model with all the covariates included $(\mathrm{N}=673)$.

\begin{tabular}{|c|c|c|c|c|c|}
\hline & $\begin{array}{l}\text { Covariate } \\
\text { requency }(\mathrm{N})\end{array}$ & $\begin{array}{l}\text { Persistent } \\
\text { pain }(\%)\end{array}$ & $\begin{array}{l}\text { Crude } \\
\text { OR }\end{array}$ & $\begin{array}{l}\text { Adjusted } \\
\text { OR }\end{array}$ & $\begin{array}{l}95 \% \mathrm{Cl} \text { for } \\
\text { adjusted OR }\end{array}$ \\
\hline Mouse time (continuous, effect of 10) & . & . & 1.16 & 1.16 & $0.92-1.48$ \\
\hline \multicolumn{6}{|l|}{ Mouse time categories } \\
\hline $0-<10$ hours/week & 164 & 63 & 1 & 1 & $\cdot$ \\
\hline $10-<20$ hours/week & 258 & 70 & 1.39 & 1.56 & $0.96-2.55$ \\
\hline 20-<30 hours/week & 161 & 70 & 1.35 & 1.52 & $0.88-2.65$ \\
\hline$\geq 30$ hours/week & 67 & 70 & 1.39 & 1.47 & $0.69-3.21$ \\
\hline Keyboard time (continuous, effect of 10 hours/week) & $\cdot$ & $\cdot$ & 1.03 & 1.25 & $0.85-1.86$ \\
\hline \multicolumn{6}{|l|}{ Keyboard time categories } \\
\hline $0-<5$ hours/week & 211 & 70 & 1 & 1 & . \\
\hline $5-<10$ hours/week & 215 & 65 & 0.80 & 0.82 & $0.49-1.36$ \\
\hline $10-<15$ hours/week & 130 & 66 & 0.85 & 0.75 & $0.42-1.37$ \\
\hline$\geq 15$ hours/week & 108 & 74 & 1.24 & 1.66 & $0.86-3.23$ \\
\hline Forearm-wrist support during mouse use & 559 & 69 & 1.63 & 1.50 & $0.83-2.68$ \\
\hline Abnormal mouse position & 34 & 65 & 0.85 & 1.20 & $0.52-2.94$ \\
\hline Forearm-wrist support during keyboard use & 251 & 67 & 0.89 & 0.94 & $0.62-1.43$ \\
\hline Abnormal keyboard position & 99 & 71 & 1.16 & 1.24 & $0.73-2.16$ \\
\hline Unadjusted chair & 24 & 63 & 0.77 & . & - \\
\hline Unadjusted desk & 139 & 69 & 1.06 & 1.31 & $0.79-2.22$ \\
\hline Dissatisfaction with physical workplace arrangement & 125 & 64 & 0.80 & 0.62 & $0.36-1.09$ \\
\hline High job demands & 299 & 69 & 1.07 & 1.12 & $0.67-1.87$ \\
\hline Low job control & 273 & 70 & 1.20 & 1.10 & $0.66-1.84$ \\
\hline Low job support & 312 & 69 & 1.05 & 0.96 & $0.65-1.42$ \\
\hline High time pressure & 207 & 74 & 1.56 & 1.74 & $1.15-2.67$ \\
\hline High strain & 118 & 69 & 1.09 & 0.91 & $0.42-1.97$ \\
\hline Present pain in the region(s) at baseline & 351 & 73 & 1.67 & 1.69 & $1.15-2.48$ \\
\hline No pain in other regions at baseline & 22 & 32 & 1 & 1 & - \\
\hline Pain in 1-2 other regions at baseline & 182 & 63 & 3.59 & 3.40 & $1.24-10.4$ \\
\hline Pain in 3-4 other regions at baseline & 304 & 69 & 4.71 & 4.65 & $1.73-14.0$ \\
\hline Pain in $\geq 5$ other regions at baseline & 161 & 78 & 7.44 & 6.28 & $2.22-19.7$ \\
\hline Female gender & 530 & 71 & 1.70 & 1.63 & $1.05-2.51$ \\
\hline Age (continuous, effect of 10 years) & $\cdot$ & $\cdot$ & 1.10 & 1.17 & $0.94-1.47$ \\
\hline Body mass index $\geq 30$ & 55 & 78 & 1.72 & 1.42 & $0.69-3.11$ \\
\hline Medical condition & 65 & 71 & 1.15 & 1.11 & $0.59-2.17$ \\
\hline High leisure-time physical activity & 279 & 67 & 0.89 & 0.95 & $0.65-1.40$ \\
\hline Negative affectivity & 119 & 66 & 0.86 & 0.82 & $0.51-1.34$ \\
\hline Type-A behavior & 90 & 59 & 0.63 & 0.55 & $0.33-0.93$ \\
\hline
\end{tabular}


Table 3. Risk factors for persistent pain, by specific regions and combined arm outcomes according to different criteria for persistence. (See the text.) Results from the logistic regression analyses of models including questionnaire mouse and keyboard times and covariates with effects at $\mathrm{P} \leq 0.25$. ( $\mathrm{OR}=$ odds ratio, $95 \% \mathrm{Cl}=95 \%$ confidence intervals)

\begin{tabular}{|c|c|c|c|c|c|c|c|c|c|c|c|c|}
\hline & \multirow{2}{*}{\multicolumn{2}{|c|}{ Elbow $(\mathrm{N}=289)$}} & \multirow{2}{*}{\multicolumn{2}{|c|}{ Forearm $(\mathrm{N}=293)$}} & \multirow{2}{*}{\multicolumn{2}{|c|}{ Wrist-hand $(\mathrm{N}=429)$}} & \multicolumn{6}{|c|}{ Arm } \\
\hline & & & & & & & $\begin{array}{r}3,3,3 \\
(N=\end{array}$ & $\begin{array}{l}\text { criterion } \\
=673)\end{array}$ & $\begin{array}{r}3,5,7 \mathrm{C} \\
\quad(\mathrm{N}=\end{array}$ & $\begin{array}{l}\text { criterion } \\
=673)\end{array}$ & $\begin{array}{r}3,6,9 \\
\text { (N }\end{array}$ & $\begin{array}{l}\text { criterion } \\
=673)\end{array}$ \\
\hline & $\begin{array}{l}\text { Adjustec } \\
\text { OR }\end{array}$ & d $95 \% \mathrm{Cl}$ & $\begin{array}{l}\text { Adjusted } \\
\text { OR }\end{array}$ & $95 \% \mathrm{Cl}$ & \multicolumn{2}{|c|}{$\begin{array}{l}\text { Adjusted } 95 \% \mathrm{Cl} \\
\text { OR }\end{array}$} & \multicolumn{2}{|c|}{$\begin{array}{l}\text { Adjusted } 95 \% \mathrm{Cl} \\
\quad \text { OR }\end{array}$} & \multirow{2}{*}{$\begin{array}{c}\begin{array}{c}\text { Adjusted } \\
\text { OR }\end{array} \\
1.19\end{array}$} & \multirow{2}{*}{$\begin{array}{l}\text { d } 95 \% \mathrm{Cl} \\
0.95-1.49\end{array}$} & \multicolumn{2}{|c|}{$\begin{array}{l}\text { Adjusted } 95 \% \mathrm{Cl} \\
\text { OR }\end{array}$} \\
\hline $\begin{array}{l}\text { Iviouse tıme (contınu- } \\
\text { ous, effect of } \\
10 \text { hours/week) }\end{array}$ & 1.19 & $0.86-1.64$ & 1.03 & $0.71-1.49$ & 1.25 & $0.93-1.68$ & 1.09 & $0.88-1.35$ & & & 1.37 & $1.09-1.73$ \\
\hline $\begin{array}{l}\text { Keyboard time (contin- } \\
\text { uous, effect of } \\
10 \text { hours/week) }\end{array}$ & 1.36 & $0.78-2.40$ & 1.22 & $0.71-2.14$ & 0.96 & $0.61-1.53$ & 1.14 & $0.81-1.61$ & 1.21 & $0.85-1.74$ & 1.12 & $0.78-1.64$ \\
\hline $\begin{array}{l}\text { Forearm-wrist support } \\
\text { during mouse use }\end{array}$ & . & . & 1.45 & $0.58-3.57$ & 2.14 & $1.09-4.15$ & 1.45 & $0.87-2.48$ & 1.53 & $0.89-2.62$ & . & . \\
\hline $\begin{array}{l}\text { Forearm-wrist support } \\
\text { during keyboard use }\end{array}$ & . & . & 0.60 & $0.32-1.10$ & . & . & . & . & . & . & $\cdot$ & . \\
\hline $\begin{array}{l}\text { Abnormal keyboard } \\
\text { position }\end{array}$ & . & . & 1.05 & $0.91-4.49$ & . & . & . & . & . & . & · & . \\
\hline Unadjusted desk & . & . & 2.21 & $1.06-4.91$ & . & . & . & $\cdot$ & . & $\cdot$ & 1.36 & $0.81-2.34$ \\
\hline $\begin{array}{l}\text { Dissatisfaction with } \\
\text { physical work place } \\
\text { arrangement }\end{array}$ & 0.53 & $0.26-1.09$ & . & $\cdot$ & . & . & 0.77 & $0.49-1.21$ & 0.75 & $0.47-1.20$ & 0.54 & $0.32-0.94$ \\
\hline High time pressure & 1.73 & $0.94-3.29$ & . & . & . & . & 1.46 & $0.99-2.17$ & 1.68 & $1.12-2.56$ & 1.87 & $1.20-2.98$ \\
\hline High strain & . & . & 1.28 & $0.58-3.00$ & . & . & . & $\cdot$ & . & . & . & . \\
\hline $\begin{array}{l}\text { Present pain in the } \\
\text { region(s) at baseline }\end{array}$ & 1.70 & $0.97-3.01$ & . & $\cdot$ & 1.85 & $1.13-3.03$ & 1.54 & $1.09-2.20$ & 1.63 & $1.13-2.37$ & 1.84 & $1.24-2.74$ \\
\hline $\begin{array}{l}\text { Pain in } 1-2 \text { other } \\
\text { regions at baseline }\end{array}$ & 3.44 & $0.58-27.5$ & 17.1 & $2.72-334$ & 2.07 & $0.53-8.06$ & 3.17 & $1.18-9.48$ & 3.43 & $1.27-10.3$ & 2.74 & $1.05-7.37$ \\
\hline $\begin{array}{l}\text { Pain in 3-4 other } \\
\text { regions at baseline }\end{array}$ & 4.07 & $0.70-31.9$ & 13.7 & $2.32-262$ & 3.35 & $0.88-12.8$ & 3.74 & $1.42-11.0$ & 4.63 & $1.75-13.7$ & 3.89 & $1.52-10.3$ \\
\hline $\begin{array}{l}\text { Pain in } \geq 5 \text { other } \\
\text { regions at baseline }\end{array}$ & 5.63 & $0.92-45.8$ & 21.7 & $3.47-425$ & 3.74 & $0.93-15.1$ & 4.97 & $1.82-15.2$ & 6.13 & $2.21-18.9$ & 4.36 & $1.62-12.1$ \\
\hline Female gender & 2.52 & $1.30-4.91$ & . & . & . & . & 1.40 & $0.92-2.13$ & 1.54 & $1.00-2.36$ & 1.42 & $0.89-2.24$ \\
\hline $\begin{array}{l}\text { Age (continuous, } \\
\text { effect of } 10 \text { years) }\end{array}$ & 1.33 & $0.95-1.88$ & 1.34 & $0.98-1.84$ & . & . & . & $\cdot$ & 1.18 & $0.96-1.46$ & · & . \\
\hline Negative affectivity & 1.78 & $0.81-4.19$ & 0.57 & $0.27-1.19$ & · & . & . & $\cdot$ & . & . & . & . \\
\hline Type-A behavior & . & . & . & . & 0.48 & $0.25-0.93$ & 0.64 & $0.39-1.06$ & 0.55 & $0.33-0.93$ & 0.68 & $0.40-1.20$ \\
\hline
\end{tabular}

High time pressure increased the risk of arm pain (3,5,7 criterion and 3,6,9 criterion), and the same tendency was found for elbow pain and arm pain (3,3,3 criterion). Traditional psychosocial workplace factors (high job demands, low job control, low work-related social support, high strain) were not risk factors.

Present pain in a region increased the risk of persistent pain for all the outcomes, except for the forearm. Any 12-month pain in regions outside the right elbow, forearm, and wrist-hand regions seemed to have rather consistent effects for all outcomes. The risk increased by the number of other regions with pain, but the risk estimates for $1-2,3-4$, and $\geq 5$ regions did not significantly differ for any of the examined outcomes. However, when the categories were collapsed into a dichotomous variable (other regional pain yes or no), the effect was statistically significant at $\mathrm{P} \leq 0.05$. The effects of other regional pain were high for persistent forearm pain, and they had wide confidence limits due to the few baseline forearm cases without pain in other regions $(\mathrm{N}=10)$ and persistent pain at follow-up $(\mathrm{N}=2)$.
Female gender increased the risk of persistent pain in the elbow and arm with the 3,5,7 criterion. Type-A behavior reduced the risk of persistent wrist-hand pain and arm pain (3,5,7 criterion). Higher age, high BMI, presence of a medical condition, low leisure-time physical activity, and negative affectivity were not risk factors.

A total of $31 \%$ of the respondents reported that they had made some changes in their work with computer during the follow-up period as a result of pain in the arms or neck. Altogether 161 (24\%) changed workplace arrangements or type of pointing device. Twelve (1.8\%) reduced their computer worktime. Forty-six (7.6\%) respondents had changed hands or used their hands interchangeably when operating the mouse. The effects of these changes were not statistically significant with respect to the prognosis of severe regional or combined arm pain. Neither were the effects of changes in mouse or keyboard times ( \pm 5 hours/week) from the baseline to the follow-up (data not shown). Interaction terms between the ergonomic factors and mouse and keyboard times were not statistically significant (data not shown). 


\section{Objective data on computer use}

The distributions of objective computer data are shown in table 4 . The relations with persistent arm pain (3,5,7 criterion) are presented in table 5. Mouse and keyboard times, micropauses and speed, and keyboard average activity periods were not statistically significant risk factors for the outcomes. An increase in the average activity periods with the mouse seemed to protect against persistent pain. The corresponding results for persistent wrist-hand pain and the other two persistent arm pain variables (3,3,3 criterion and 3,6,9 criterion) were similar (data not shown). There were no significant effects on persistent elbow pain. Persistent forearm pain seemed to be prevented by increasing mouse speed (effect of 15 clicks/minute: OR $0.20,95 \%$ CI 0.04-0.92) and increasing average activity periods with the keyboard (effect of 10 seconds: OR $0.40,95 \%$ CI $0.16-0.89$ ). There were no statistically significant interactions between mouse time and the other mouse-related variables or between keyboard time and related variables (data not shown). On the average, objective aspects of computer use were similar from the baseline to the follow-up (table 4).
Table 4. Distribution of the questionnaire and objectively recorded characteristics of computer work at baseline and the differences from the baseline questionnaire to the follow-up.

\begin{tabular}{|c|c|c|c|c|c|}
\hline & \multicolumn{3}{|c|}{ Baseline } & \multicolumn{2}{|c|}{$\begin{array}{l}\text { Baseline } \\
\text { minus } \\
\text { follow-up }\end{array}$} \\
\hline & Mean & SD & Range & Mean & SD \\
\hline \multicolumn{6}{|l|}{ Questionnaire } \\
\hline Mouse time (hours/week) & 16.3 & 9.3 & $0-37$ & 1.7 & 8.8 \\
\hline Keyboard time (hours/week) & 8.5 & 5.8 & $0-37$ & 0.96 & 5.8 \\
\hline \multicolumn{6}{|l|}{ Objective computer use variables } \\
\hline Mouse time (hours/week) & 6.2 & 3.6 & $0.00-18.3$ & -0.59 & 3.6 \\
\hline Keyboard time (hours/week) & 1.2 & 1.0 & $0-6.6$ & -0.13 & 0.8 \\
\hline \multicolumn{6}{|l|}{ Micropauses (number/hour) } \\
\hline Mouse time & 43.7 & 14.6 & $0-121$ & -1.4 & 12.5 \\
\hline Keyboard time & 33.1 & 28.2 & $0-175$ & -1.3 & 21.0 \\
\hline $\begin{array}{l}\text { Mouse speed (clicks/ } \\
\text { minute of mouse time) }\end{array}$ & 25.1 & 7.4 & $2.7-53.2$ & -0.14 & 4.4 \\
\hline $\begin{array}{l}\text { Keying speed (keystrokes/ } \\
\text { minute of keyboard time) }\end{array}$ & 147 & 26 & $92-253$ & -1.4 & 15.5 \\
\hline \multicolumn{6}{|c|}{ Average activity periods (seconds) } \\
\hline $\begin{array}{l}\text { Mouse } \\
\text { Keyboard }\end{array}$ & $\begin{array}{r}153 \\
16.2\end{array}$ & $\begin{array}{r}134 \\
10.2\end{array}$ & $\begin{array}{c}19-1311 \\
5-100\end{array}$ & $\begin{array}{r}7.4 \\
-0.46\end{array}$ & $\begin{array}{r}133 \\
7.6\end{array}$ \\
\hline
\end{tabular}

Table 5. Objectively recorded computer use and persistent arm pain (3,5,7 criterion), controlled for effects of the questionnaire covariates with effects statistically significant at $\mathrm{P} \leq 0.25$, see table $3(\mathrm{~N}=282)$. (OR $=$ odds ratio, $95 \% \mathrm{Cl}=95 \%$ confidence interval)

\begin{tabular}{|c|c|c|c|c|c|}
\hline Objective computer work characteristic & $\begin{array}{l}\text { Covariate } \\
\text { frequency } \\
\text { (N) }\end{array}$ & $\begin{array}{l}\text { Persistent } \\
\text { arm pain } \\
(\%)\end{array}$ & $\begin{array}{c}\text { Crude } \\
\text { OR }\end{array}$ & $\begin{array}{c}\text { Adjusted } \\
\text { OR }\end{array}$ & $95 \% \mathrm{Cl}$ \\
\hline Mouse time (effect of an increase of 5 hours/week) & $\cdot$ & . & 0.90 & 1.16 & $0.67-2.04$ \\
\hline $0-<5$ hours/week & 112 & 76 & 1 & • & $\cdot$ \\
\hline $5-<10$ hours/week & 126 & 75 & 0.93 & . & . \\
\hline$\geq 10$ hours/week & 42 & 74 & 0.90 & . & . \\
\hline Mouse micropauses (effect of 30 micropauses/hour) & · & $\cdot$ & 1.05 & 0.77 & $0.35-1.66$ \\
\hline 0-30 micropauses/hour & 48 & 69 & 1 & • & $\cdot$ \\
\hline $30-<60$ micropauses/hour & 202 & 77 & 1.50 & . & . \\
\hline$\geq 60$ micropauses/hour & 30 & 73 & 1.25 & . & . \\
\hline Mouse speed (effect of 15 clicks/minute) & . & · & 0.82 & 1.08 & $0.48-2.55$ \\
\hline $0-<15$ clicks/minute & 79 & 72 & 1 & . & $\cdot$ \\
\hline $15-<30$ clicks/minute & 135 & 79 & 1.48 & . & $\cdot$ \\
\hline$\geq 30$ clicks/minute & 66 & 70 & 0.89 & . & $\cdot$ \\
\hline Mouse average activity periods (effect of 100 seconds) & $\cdot$ & $\cdot$ & 0.74 & 0.66 & $0.45-0.91$ \\
\hline $0-<100$ seconds & 103 & 79 & 1 & • & $\cdot$ \\
\hline $100-<200$ seconds & 115 & 73 & 0.74 & . & . \\
\hline$\geq 200$ seconds & 81 & 72 & 0.70 & . & $\cdot$ \\
\hline Keyboard time (effect of an increase of 1 hour/week) & $\cdot$ & $\cdot$ & 1.16 & 1.40 & $0.76-2.64$ \\
\hline $0-<1$ hour/week & 167 & 74 & 1 & . & . \\
\hline $1-<2$ hour/week & 70 & 73 & 0.96 & $\cdot$ & $\cdot$ \\
\hline$\geq 2$ hour/week & 43 & 84 & 1.84 & . & $\cdot$ \\
\hline Keyboard micropauses (effect of 20 micropauses/hour) & $\cdot$ & $\cdot$ & 1.08 & 1.08 & $0.73-1.65$ \\
\hline 0-20 micropauses/hour & 106 & 73 & 1 & • & $\cdot$ \\
\hline 20-<40 micropauses/hour & 95 & 78 & 1.33 & . & . \\
\hline$\geq 40$ micropauses/hour & 78 & 74 & 1.09 & $\cdot$ & $\cdot$ \\
\hline Keying speed (effect of 50 keystrokes/minute) & $\cdot$ & $\cdot$ & 1.11 & 1.48 & $0.72-3.22$ \\
\hline $0-<50$ keystrokes/minute & 52 & 77 & 1 & . & . \\
\hline $50-<100$ keystrokes/minute & 110 & 72 & 0.80 & . & . \\
\hline$\geq 100$ keystrokes/minute & 118 & 76 & 0.96 & $\cdot$ & $\cdot$ \\
\hline Keying average activity periods (effect of 10 seconds) & $\cdot$ & $\cdot$ & 0.96 & 0.90 & $0.64-1.32$ \\
\hline $0-<10$ seconds & 49 & 71 & 1 & • & . \\
\hline $10-<20$ seconds & 175 & 77 & 1.31 & . & . \\
\hline$\geq 20$ seconds & 55 & 73 & 1.07 & $\cdot$ & $\cdot$ \\
\hline
\end{tabular}


Changes in these aspects from the baseline to the follow-up had no statistically significant effects on persistent arm pain (data not shown).

\section{Discussion}

Our study dealt with the prognosis of severe arm pain among computer users. We chose to study severe arm pain prognosis because of its potential clinical relevance. We used a clinical yes-no approach to define the cases and outcomes. Twelve percent of the participants reported "quite a lot" of trouble or more due to elbow, forearm, or wrist-hand pain during the year prior to the administration of the baseline questionnaire. At the follow-up, 60-67\% of these baseline cases had only some trouble or less, and $20-25 \%$ had none at all or very little (table 1). In this sense, the prognosis seemed favorable for most of the cases. However, in most cases, pain reduction was due to moving one or two categories down on the pain scale (table 1). To be confident that a pain reduction had actually occurred, pain reduction of at least three categories on the pain scale was required. With the use of this criterion the prognosis was naturally poorer. Only 26\%, 32\%, and 33\% (hand, elbow, and forearm cases, respectively) had such a substantial pain reduction.

We examined how the prognosis for the elbow, forearm, and wrist-hand regions and arm pain was affected by work-related and personal risk factors. We found a few sporadic statistically significant effects, some of which were in the opposite direction of expectations. The data did not support assumptions that "severe" baseline pain had a better prognosis if the weekly duration of mouse and keyboard work was short, if there were many micropauses, low speed, or short average activity periods. There were no statistically significant effects of changes (increments or decrements in hours per week) in mouse or keyboard work from the baseline to the follow-up. The study benefited from objectively measured mouse and keyboard work. The $42 \%$ who returned objective data differed from those who did not by having slightly higher self-reported mouse time and a poorer prognosis. It is difficult to imagine, however, how such differential selection would create a false negative association between objective computer work aspects and the outcomes examined.

The questionnaire mouse and especially keyboard times were overestimated when compared with the objectively measured times (table 4). This finding is in accordance with the results of other studies $(15,16)$. However, there were no statistically significant effects of mouse and keyboard times on the prognosis of arm pain, whether self-reported or objectively recorded. For our material, objective keyboard time turned out to be very low, mean 1.2 hours/week, maximum 6.6 hours/ week, and keying at such low exposure levels may not have any adverse effects.

Self-reported ergonomic conditions were based on factual, easily observed basic conditions, which may affect work posture and load. The ergonomic covariates had no consistent statistically significant effects on the prognosis of severe regional or combined arm pain. Only a few of the respondents $(\mathrm{N}=34)$ reported an abnormal mouse position, the result being wide confidence limits (table 1), but otherwise the sample size and covariate distributions did not indicate that the negative results were due to a lack of study power. We do not believe that these negative results are due to measurement errors. The inclusion of "dissatisfaction with workplace arrangement" in the models did not result in overadjustment with respect to the other ergonomic factors, as their effects were similar in models with and without this covariate.

At the follow-up, changes in computer work owing to pain in the neck, shoulders, arms, or hands were reported. Altogether $31 \%$ had made such changes, mainly in workplace arrangements or types of input devices. Few $(1.8 \%)$ had reduced their computer worktime because of pain. These spontaneous interventions probably reflect common beliefs that arm or neck pain states are related to computer work and may improve if ergonomic conditions are changed. The results did not support this assumption.

Traditional psychosocial workplace factors (demand, control, support, strain) had no statistically significant influence on arm pain prognosis. In a previous study of Danish industrial and service workers, a low recovery rate for shoulder tendonitis was associated with high job demands and low social support (17). Another study found that high job demands among newspaper workers predicted the persistence of musculoskeletal pain (18). High time pressure tended to increase the risk for persistent pain in our study. The "time pressure" variable collected information about the ability to meet deadlines and quality requirements. This variable could be a specific risk factor in this occupational group due to certain circumstances related to the technicians' job functions.

Factors with strong effects on the prognosis were present pain in the right elbow, forearm, and wrist-hand regions at baseline and any pain during the past 12 months in regions outside the case regions. Both factors increased the risk of persistent pain. This is not a surprising finding for present pain. Pain in multiple regions may indicate a more-severe pain problem, which may possibly be more related to aspects of personal pain perception than to local pathology. This possibility would be in accordance with an increasingly poorer 
prognosis as a result of an increase in the number of other regions with pain. This pattern was found, but with no statistically significant difference between the effects of $1-2,3-4$, and $\geq 5$ regions with pain. Thus any musculoskeletal pain in other regions seems to imply a poorer prognosis.

Among the personal factors, there was a tendency for women to have a poorer prognosis than men and for a high degree of type-A behavior to be associated with a better prognosis than a low degree was. We found no statistically significant consistent effects for age, negative affectivity, low leisure-time physical activity, high BMI, or presence of a medical condition. Studies of prognosis for musculoskeletal pain in other regions have found higher age and female gender to inhibit recovery and high levels of leisure-time sporting activities to contribute to the disappearance of symptoms (19-21). These different results may depend on several differences between the studies, including the regions under study.

We aimed at case definitions that might have clinical implications. However, only $9 \%$ reported sickness absence during the follow-up due to pain in the right elbow, forearm, or wrist-hand region. We do not have Danish population data on sickness absence due to arm pain for comparison, however. A Dutch population study reported a sickness absence rate of $16 \%$ due to any elbow or wrist-hand pain (8). These sickness absence rates may not be completely comparable due to national differences, but they may indicate that the pain states of our cases were not so severe. At the follow-up, 11 (1.6\%) participants without employment reported that their unemployment was partly due to elbow, forearm, or hand pain, and $4(0.6 \%)$ stated that it was exclusively due to such pain. Among the participants invited to the clinical examination $(\mathrm{N}=391)$, physical disability measured by DASH was mild to moderate, the mean score being 21.0 (SD 14.9); 214 (55\%) had a DASH score that was below 20; and 21 persons $(5.4 \%)$ had a DASH score of $\geq 50$. Thus, among the cases with severe pain, only $5-10 \%$ experienced pain-related degrees of activity limitations, which, in our opinion, could be compared with clinical pain conditions. This finding corresponds to approximately $0.5 \%$ to $1.0 \%$ of the whole cohort. Our study was not large enough to directly address prognostic problems of clinically relevant arm pain among computer users because such pain states seem to be rare. If our results concerning less severe cases can be extrapolated to clinical cases, one would not expect any beneficial effects from changes in computer work (eg, reduced time and ergonomic changes).

The results may seem surprising if mechanical exposures are considered as major risk factors for the development and persistence of work-related pain in computer workers. Studies on incident upper-extremity pain among computer workers indicate that exposure time (computer, mouse, or keyboard times) are important risk factors $(3,5-7,13)$. This finding is in accordance with a mechanical theory for the development of computer work-related pain. One would expect then that the persistence of pain would be affected in a similar way by exposure times. This was not the case in our study, but the results should be tested in additional research. A mechanical theory on the development of computer work-related pain would further predict that poor ergonomic conditions would increase the risk for computer work-related pain. We did not find such a relationship in our study in the results on incidence data $(5,13)$. Pain in regions outside the case regions was a strong predictor of persistent arm pain and, therefore, indicated that changes in pain perception may be an interesting issue to pursue in an effort to explain incident and persistent musculoskeletal pain, whether work-related or not.

\section{Acknowledgments}

This study was sponsored by the Danish Medical Research Council (grant number 9801292) and the Danish Ministry of Employment, via the National Work Environment Authority (grant number 20000010486).

\section{References}

1. Danmarks Statistik. Danmark et IT samfund. Danmarks Statistik; 2003.

2. Burr H, Bjorner JB, Kristensen TS, Tüchsen F, Bach E. Trends in the Danish work environment in 1990-2000 and their associations with labor-force changes. Scand J Work Environ Health 2003;29(4):270-9.

3. Jensen C. Development of neck and hand-wrist symptoms in relation to duration of computer use at work. Scand J Work Environ Health 2003;29(3):197-205.

4. Andersen JH, Thomsen JF, Overgaard E, Lassen CF, Brandt LP, Vilstrup I, et al. Computer use and carpal tunnel syndrome: a 1-year follow-up study. JAMA 2003;289(22):29639.

5. Kryger AI, Andersen JH, Lassen CF, Brandt LPA, Vilstrup I, Overgaard E, et al. Does computer use pose an occupational hazard for forearm pain; from the NUDATA study [electronical paper]. Occup Environ Med 2003;60(11):e14. [Accessed: November 2003; available from: http://oem.bmjjournals.com/ ]

6. Gerr F, Marcus M, Ensor C, Kleinbaum D, Cohen S, Edwards A, et al. A prospective study of computer users, I: study design and incidence of musculoskeletal symptoms and disorders. Am J Ind Med 2002;41(4):221-35.

7. Nakazawa T, Okubo Y, Suwazono Y, Kobayashi E, Komine $\mathrm{S}$, Kato N, et al. Association between duration of daily VDT use and subjective symptoms. Am J Ind Med 2002;42(5):4216.

8. Picavet HS, Schouten JS. Musculoskeletal pain in the Nether- 
lands: prevalences, consequences and risk groups, the DMC (3)-study. Pain 2003;102(1-2):167-78.

9. Feuerstein M, Huang GD, Haufler AJ, Miller JK. Development of a screen for predicting clinical outcomes in patients with work-related upper extremity disorders. J Occup Environ Med 2000;42(7):749-61.

10. Estlander A-M, Takala E-P, Viikara-Juntura E. Do psychological factors predict changes in musculoskeletal pain?. A prospective two-year follow-up study of a working population. J Occup Environ Med 1998;40(5):445-53.

11. Kristensen TS, Borg V, Hannerz H. Socioeconomic status and psychosocial work environment: results from a Danish national study. Scand J Public Health 2002;Suppl 59:41-8.

12. Karasek R, Brisson C, Kawakami N, Houtman I, Bongers P, Amick B. The Job Content Questionnaire (JCQ): an instrument for internationally comparative assessments of psychosocial job characteristics. J Occup Health Psychol 1998;3(4):322-55.

13. Lassen CF, Mikkelsen S, Kryger AI, Brandt LPA, Overgaard E, Vilstrup I, et al. Elbow and wrist/hand symptoms among 6943 computer operators: a 1-year follow-up study (the NUDATA study). Am J Ind Med 2004;30(5):359-409.

14. Hudak PL, Amadio PC, Bombardier C. Development of an upper extremity outcome measure: the DASH (disabilities of the arm, shoulder and hand). Am J Ind Med 1996;29(6):602-8.

15. Homan MM, Armstrong TJ. Evaluation of three methodologies for assessing work activity during computer use. AIHA J
2003;64(1):48-55.

16. Faucett J, Rempel D. Musculoskeletal symptoms related to video display terminal use: an analysis of objective and subjective exposure estimates. AAOHN J 1996;44(1):33-9.

17. Bonde JP, Mikkelsen S, Andersen JH, Fallentin N, Baelum J, Svendsen SW, et al. Prognosis of shoulder tendonitis in repetitive work: a follow up study in a cohort of Danish industrial and service workers [electronical paper]. Occup Environ Med 2003;60(9):E8. [Accessed: September 2003; available from: http://oem.bmjjournals.com/]

18. Cole DC, Manno M, Beaton D, Swift M. Transitions in selfreported musculoskeletal pain and interference with activities among newspaper workers. J Occup Rehabil 2002;12(3): 16374.

19. Cassou B, Derriennic F, Monfort C, Norton J, Touranchet A. Chronic neck and shoulder pain, age, and working conditions: longitudinal results from a large random sample in France. Occup Environ Med 2002;59(8):537-44.

20. Kaergaard A, Andersen JH. Musculoskeletal disorders of the neck and shoulders in female sewing machine operators: prevalence, incidence, and prognosis. Occup Environ Med 2000;57(8):528-34.

21. Miranda H, Viikari-Juntura E, Martikainen R, Riihimäki H. A prospective study on knee pain and its risk factors. Osteoarthritis Cartilage 2002;10(8):623-30.

Received for publication: 5 April 2004 